\title{
LA INFLUENCIA DE ALFONSO DE CARTAGENA EN LA COMPENDIOSA HISTORIA HISPANICA DE RODRIGO SÁNCHEZ DE ARÉVALO"
}

\author{
Guillermo Alvar Nuño \\ Universidad de Alcalá \\ guillermo.alvar@uah.es
}

A mi familia y amigos, por su apoyo. A Rudy y a Antonio, también por su apoyo. A Antonio y a Tomás, que me introdujeron en la senda del Humanismo. A Sara y Jaime, nuevos compañeros en el camino.

\section{La relación entre Alfonso de Cartagena y Rodrigo Sánchez de Arévalo}

En 1456, Alfonso de Cartagena escribía lo siguiente en el prólogo de su Anacephaleosis ${ }^{1}$ :

Hac itaque intentione motus conscribere feceram arborem quandam genealogiae regum Hispaniae, eorum gesta aliquantulum miscens, ut nec historiae prolixitatem, nec arboris breuitatem haberet, sed quodam mediocri modo historiali latitudini et arboreae breuitati responderet; illique excellentissimo ac indelebilis memoriae regi, honestorum studiorum auidissimo, qui nuper ab humanis oculis ad superos euocatus est, dedicaueram. At cum particula prima suae regiae maiestati tradita, transitus eius interuenisset, quieuit opusculum illud, aliis temporibus per me, uel alium altioris et abundantioris ingenii, forte, si placuerit diuina mansuetudini, prosequendum².

* Este estudio se inscribe en el marco del Proyecto I+D+i del MINECO: DHuMAR: Humanidades Digitales, Edad Media y Renacimiento. 1. Poesía 2. Traducción (FFI2013-44286-P), de la Universidad de Alcalá, y se publica en colaboración con el proyecto de investigación Alfonso de Cartagena. Obras Completas FFI 2014-55902-P y FFI 2017-84858-P (MINECO y MICINN, Gobierno de España).

${ }^{1}$ El texto latino ha sido extraído de la edición de la obra realizada por Andreas Wechel (Frankfurt, 1579) bajo el título Hipanicarum scriptores aliquot, tomo II, p. 611.

${ }^{2}$ Trad.: Así que, movido por esta intención, me había propuesto escribir un árbol con las genealogías de los reyes de Hispania, mezclándolas con un poquito de sus gestas, para que no tuviera ni la extensión 
Hay tres datos que merece la pena destacar: el primero, que al final de su vida y tras una intensa vida diplomática, se decidió a escribir una obra histórica, y a escribirla en latín. En segundo lugar, que iba dirigida a Juan II, bajo cuyo amparo desarrolló su actividad eclesiástica y diplomática. A él le presentó, como se lee, un fragmento de su trabajo ${ }^{3}$. Sin embargo, en 1454 murió el rey y la Anacephaleosis, que había sido escrita motu proprio, no por encargo, y sin responder a ninguna finalidad política inmediata, tuvo un reconocimiento menos elevado del esperado. Fue acogida con frialdad en el círculo cortesano castellano mas, a pesar de ver truncado su proyecto, Alfonso de Cartagena se decidió a terminarlo y dedicarlo al cabildo catedralicio de su diócesis, Burgos, donde gozó de gran éxito ${ }^{4}$. Por último, hace mención a que su proyecto historiográfico habría de ser continuado por él mismo o por alguien de gran sabiduría. ¿Tenía ya Alfonso de Cartagena en mente que un discípulo suyo, Rodrigo Sánchez de Arévalo, podría continuar con mejor suerte la tarea que ocupó los últimos años de su vida?

No es cuestión de esbozar la biografía de ninguno de estos dos personajes, por lo demás bien estudiados. Sin embargo, unas pocas líneas pueden explicar la relación de Sánchez de Arévalo con respecto a su maestro ${ }^{5}$. Para ambos, el

de una historia ni la brevedad de un árbol, sino que tuviera una proporción intermedia entre la amplitud histórica y la brevedad arbórea; y la había dedicado a mi rey excelentísimo y de imborrable recuerdo, deseosísimo de estudios honestos, el cual hace poco ha sido llamado a los cielos de entre los ojos de los hombres. Pero, puesto que después de haberle entregado una primera partecita a su regia majestad le sobrevino la muerte, se paralizó esta obrita hasta ser continuada en otro momento por mí o por alguien con una sabiduría mayor y más abundante.

${ }^{3}$ Según Laurette Godinas, «Alonso de Cartagena y la así llamada Anacephaleosis o las vicisitudes de un texto histórico del s. Xv», en Visiones y crónicas medievales, ed. de A. González, L. von der Walde y C. Company, México, Universidad Autónoma Metropolitana, 2002, pp. 131-144, se trataría de la primera parte y, posiblemente, algo de la segunda, pero nada más allá de un borrador incompleto (pp. 137-139). Luis Fernández Gallardo, Alonso de Cartagena. Una biografia política en la Castilla del siglo XV, León, Junta de Castilla y León, 2002, p. 281, afirma que en la Anacephaleosis el capítulo LIV constituye un cambio crítico en la composición de la obra: antes de él, se seguía cuidadosamente la crónica de Jiménez de Rada; después, su alcance fue mucho más local. Por eso, la parte que se presentó a Juan II debió ser la que va de los capítulos I al LIV.

${ }^{4}$ Cfr. L. Fernández Gallardo, Alonso de Cartagena ..., ed. cit., pp. 280-281.

${ }^{5}$ Las principales biografías sobre Sánchez de Arévalo son las de Teodoro Toni, «Don Rodrigo Sánchez de Arévalo (1404-1470). Su personalidad y actividades. El tratado De pace et bello», en Anuario de Historia del Derecho Español, 1935, pp. 97-369; Richard H. Trame, Rodrigo Sánchez de Arévalo (14041470), Spanish Diplomat and Champion of the Papacy, Washington, The Catholic University of America, 1958; Mario Penna, Prosistas castellanos del siglo XV, vol. 1, Madrid, Atlas, 1959, pp. LXX-XCIX; y Juan María Laboa, Rodrigo Sánchez de Arévalo, Alcaide de Sant'Angelo, Madrid, Fundación Universitaria Española, 1973. A estas hay que añadir las de José Manuel Ruiz Vila y Vicente Calvo Fernández, «El primer tratado de pedagogía del humanismo español. Introducción, edición crítica y traducción del Breuis tractatus de arte, disciplina et modo alendi erudiendi filios, pueros et iunenes (ca. 1453) de Rodrigo Sánchez de Arévalo», en Hesperia. Anuario de Filología Hispánica, 3 (2000), pp. 35-81, y la de José Manuel Ruiz Vila, El Speculum uite humane (1468) de Rodrigo Sánchez de Arévalo. Introducción, edición crítica 
Concilio de Basilea fue sin duda un jalón que marcó sus vidas. Arévalo llegó allí en 1433, probablemente con una posición menor en la embajada que envió Juan II a defender los intereses castellanos y de la que formaba parte Alfonso de Cartagena. Sus habilidades y su dedicación le permitieron obtener puestos de relevancia entre los asamblearios, tanto es así que en 1436 obtuvo como premio el beneficio eclesiástico de una ración en la catedral de Burgos, ofrecida sin lugar a dudas por su obispo, Alfonso de Cartagena, que debió fijarse en él y comenzó a apadrinarlo para atraérselo a su esfera de poder. En 1438, con motivo de la suspensión del Concilio por la peste que azotaba la ciudad de Ferrara (adonde había trasladado Eugenio IV el cónclave), Arévalo acudió en un viaje accidentado a la corte de Alberto II de Habsburgo como parte de la legación castellana que presidía Alfonso de Cartagena y que tenía por motivo ganarse el apoyo de los alemanes a la causa papal, dentro del enfrentamiento que se estaba dando entre el sumo pontífice y el bando conciliarista. A lo largo de las negociaciones, Sánchez de Arévalo ejerció como notario público. Al prelado burgalés debieron gustarle definitivamente los talentos de su protegido, pues a la vuelta de esta misión le concedió como recompensa una canonjía en Burgos ${ }^{6}$.

Poco después, y para defender sus intereses como consecuencia del Concilio de Basilea, Juan II nombró a Sánchez de Arévalo consejero y secretario $^{7}$, y lo envió como embajador a diferentes reyes y príncipes en calidad de

y traducción, Madrid, Universidad Complutense, Tesis Doctoral, 2008, pp. 45-59; y José Manuel Ruiz Vila, «Rodrigo Sánchez de Arévalo: Un hombre del Renacimiento», en Torre de los Lujanes, 65 (2009), pp. 125-138. Ponen el acento en la carrera diplomática de Arévalo, Antonio López Fonseca y José Manuel Ruiz Vila, Rodrigo Sánchez de Arévalo. Discursos al servicio de la Corona de Castilla, Madrid, Escolar y Mayo, 2013; y en su última etapa como escritor, la que tuvo mientras fue alcaide de Sant'Angelo durante sus últimos años de vida, Tomás González Rolán, José Miguel Baños Baños y Antonio López Fonseca, Ex Castro. Cartas desde la prisión papal de Sant'Angelo entre los humanistas de la Academia Romana y su alcaide, Rodrigo Sánchez de Arévalo, Madrid, Ediciones Clásicas, 2008; y Tomás González Rolán, José Miguel Baños Baños, Antonio López Fonseca y José Manuel Ruiz Vila, Rodrigo Sánchez de Arévalo. Epistolario completo, Madrid, Escolar y Mayo, 2016.

${ }^{6}$ Susana Guijarro González, «Jerarquía y redes sociales en la Castilla medieval: La provisión de beneficios eclesiásticos en el cabildo de la catedral de Burgos (1390-144)», en Anuario de estudios medievales, 38:1 (2008), pp. 271-299, pp. 295-296, ha demostrado que los Santamaría se rodearon en el cabildo catedralicio de Burgos, como es lógico, de servidores y familiares, siendo Arévalo uno de ellos.

${ }^{7}$ El cargo de secretario implicaba una cercanía a la figura del rey, según ha observado José Manuel Nieto Soria, Iglesia y génesis del estado moderno en Castilla (1369-1480), Madrid, ed. Complutense, 1994, p. 168: «Contrariamente a lo que puede pensarse a partir de su propia denominación, los secretarios reales no se limitaron tan solo a llevar la correspondencia particular del rey. Por el contrario, parece clara su posición como oficiales públicos de pleno derecho, aunque muy vinculados a la persona real, de cuya confianza disfrutan, lo que les va a llevar a prestar servicios políticos de muy diversa índole como consecuencia de esa confianza personal, lo que hará que lleguen a realizar desde embajadas, hasta servir como enlaces entre el rey y alguna de las instituciones clave del reino, tal como es el caso del Consejo Real. Desde luego, resulta evidente que el rey busca en ellos una capacidad administrativa solvente, pero que solo es relevante si va acompañada de una fidelidad y lealtad probadas». 
orator de la corona ${ }^{8}$, con el doble cometido de explicar la postura castellana frente al cisma papal e intentar atraerlos a la causa castellana. Desde este momento y hasta el final de su vida, Arévalo pronunció diferentes discursos en el marco de sus misiones diplomáticas, lo que le llevó por diferentes territorios europeos. Cuando no se encontraba de embajada en el extranjero, residía en Burgos, ocupado en los quehaceres cotidianos del cabildo catredalicio ${ }^{9}$, que iban desde la elaboración de estatutos capitulares hasta visitas a la corte regia por asuntos del cabildo. Desde 1456, sus embajadas se especializaron en las relaciones de Castilla con el papado.

La llegada de Pablo II a la dignidad papal supuso la culminación del cursus honorum de Rodrigo Sánchez de Arévalo. Aquel le concedió, en 1464, un cargo prestigiosísimo dentro de la Iglesia, el de alcaide de la fortaleza papal de Sant'Angelo, pues implicaba una confianza directa en quien lo ocupaba. Este cargo lo desempeñó hasta su muerte en 1470. Los últimos años de vida de Arévalo, transcurridos dentro del castillo, fueron muy productivos desde el punto de vista literario. A lo largo de este periodo redactó algunas de sus obras más importantes: el Liber de officio et munere ducis, capitanei et castellani (entre 1465 y 1467), el Speculum vite humane (1468), el tratado De pace et bello (1468), y la Compendiosa historia Hipanica (1470), además, de la prolija relación epistolar con los diferentes humanistas de la Accademia Romana encarcelados ${ }^{10}$. Aparte del cargo de alcaide, durante esta época cambió tres veces de obispado, primero a Zamora, en 1465, luego a Calahorra, en 1467 y, por último, Palencia, en 1469; obviamente, no llegó a visitar ninguna de estas sedes (Cотp. 4, 40, 79-8711):

\footnotetext{
${ }^{8}$ Es oportuno recordar las palabras de Miguel Ángel Ochoa-Brun, «La diplomacia española y el Renacimiento», en Diplomacia y Humanismo, Madrid, Fundación Pastor, 1989, pp. 27-63, p. 33, acerca del oficio de orator: «Desde siglos atrás se llamaba a los embajadores oratores (porque por su boca habla el rey que los envía)». En lo que respecta al cargo de orator, Garett Mattingly, Renaissance Diplomacy, Londres, Penguin Books, 1973, pp. 27-28, observó: «The Italians had found another term less barbarous than ambaxiator, and throughout the Renaissance diplomatic agents, sometimes of the highest ranks, were frequently referred to as orators. But in all the vulgar tongues some form of the word 'ambassador' became increasingly common, and in usage increasingly restricted to the major diplomatic agents of the major powers». Por lo tanto, las voces "embajador" y "orador" se emplearon como sinónimos, y designaban a los representantes de mayor rango de un Estado, es decir, eran el equivalente a la voz del rey ausente.

${ }^{9}$ Cfr. Luciano Serrano, Los conversos D. Pablo de Santa María y D. Alfonso de Cartagena: obispos de Burgos, gobernantes, diplomáticos y escritores, Madrid, CSIC, 1942, pp. 212-213.

${ }^{10}$ La edición más reciente de las epístolas que se intercambió Sánchez de Arévalo con los miembros de la Academia Romana es la de T. González Rolán, J. M. Baños Baños, A. López Fonseca y J. Manuel Ruiz Vila, Rodrigo... ed. cit. Es probable que la relación, cordial y se podría decir afectuosa, que Arévalo mantuvo con ellos, propiciara el cambio de impresor para la publicación de la Compendiosa historia Hispanica, cfr. Guillermo Alvar Nuño, «Rodrigo Sánchez de Arévalo y las circunstancias de la publicación del Speculum uite humane y de la Compendiosa historia Hispanica», en Ianua Classicorum. Temas y formas del mundo clásico, vol. 3, Madrid, Estudios Clásicos, 2015, pp. 313-320.

${ }^{11}$ En todas las citas de la Compendiosa historia Hispanica, sigo mi edición de la obra: Guillermo Alvar Nuño, Estudio, edición y traducción de la Compendiosa historia Hispanica de Rodrigo Sánchez de
} 
Hic felicissimus pontifex, qua die apicem summi pontificatus assumpsit de Sacri Collegii assensu, non sine singulari confidentia me indignum, sed fidum, prefectum castellanum castri sancti Angeli de Vrbe instituit, quippe qui iocalia et Ecclesie Romane thesauros fidei mee commisit, deinde pro sua animi nobilitate et munificentissima liberalitate me ipsum indignum primo ad Zamorensem ecclesiam, deinde Calagurritanam, tandem ad Palentinam transtulit ${ }^{12}$.

Llama la atención que en la vida de Alfonso de Cartagena y de Rodrigo Sánchez de Arévalo la actividad diplomática de ambos estuviera marcada por el Concilio de Basilea, y que la labor historiográfica sea consecuencia de su experiencia internacional. En el caso del primero, dice Fernández Gallardo ${ }^{13}$ :

Si se tiene en cuenta que las obras en que Alonso de Cartagena se muestra más sensible a las cualidades del saber histórico fueron compuestas en Basilea (Allegationes) o con posterioridad a dicha embajada, se impone la evidencia de que fue la experiencia basiliense, el contacto pleno y directo con las realizaciones humanísticas, lo que motivó tal revalorización. Y es que la historia ocupa una posición axial dentro del saber humanístico, no solo como una de las cinco disciplinas que integran los studia humanitatis, sino como premisa de una visión de la cultura y del destino humano, en la que, frente a la intemporalidad y anacronismo característicos de la cosmovisión medieval, se introduce una esencial dimensión historicista. La manifestación de cierta sensibilidad histórica en escritos posteriores a la experiencia basiliense adquiere, por tanto, una especial significación.

El caso de Arévalo responde a circunstancias muy similares. En su caso, el quehacer historiográfico comenzó con la Oratio $12^{14}$, que pronunció ante el papa Pío II con motivo de la conquista de Gibraltar, llevada a cabo por Juan Alonso Pérez de Guzmán, duque de Medina Sidonia, y Alonso de Arcos en

Arévalo, Madrid, Universidad Complutense, 2017, Tesis Doctoral.

${ }^{12}$ Trad.: Este pontífice tan benefactor, el día en el que asumió la cúspide del sumo pontificado con consentimiento del Sacro Colegio, me hizo prefecto alcaide de la fortaleza de Sant'Angelo de la Ciudad sin ser yo digno de ello, pero sí muy leal, lo cierto es que ha encomendado las joyas y tesoros de la Iglesia de Roma a mi lealtad; después, en su nobleza de ánimo y liberalidad generosísima me ha trasladado, siempre sin ser yo digno de ello, primero a la iglesia de Zamora, después a la de Calahorra, por último, a la de Palencia.

${ }^{13}$ Vid. L. Fernández Gallardo, Alonso..., cit., p. 278.

${ }^{14}$ Según la edición crítica de los discursos de Arévalo de Antonio López Fonseca y José Manuel Ruiz Vila, Rodrigo Sánchez de Arévalo. Discursos al servicio de la Corona de Castilla, Madrid, Escolar y Mayo, 2013. 
$1462^{15}$. En ella se alterna la crónica de los hechos con las virtudes del nuevo territorio conquistado ${ }^{16}$, es decir, narración histórica y descripción geográfica. Sánchez de Arévalo se animó a ampliar este discurso y transformarlo en un opúsculo al año siguiente ${ }^{17}$, titulado Libellus de descriptione Hispanie, y se lo dedicó a Pío II. El interés de este papa por la historia y la geografía ${ }^{18}$ de la Península Ibérica se vio espoleado gracias al Libellus y a los discursos de Arévalo acerca de Gibraltar. Entonces compuso su Breuis historia Hispanie entre los años 1463 y $1469^{19}$, la cual fue ampliada con nuevos materiales y llevada a la imprenta de Ulrich Hahn bajo el nombre de Compendiosa historia Hispanica el año mismo de su muerte (1470).

\section{La influencia de la retórica ciceroniana en el quehacer histórico de Alfonso de Cartagena y de Sánchez de Arévalo}

El padre de Alfonso de Cartagena, Pablo de Santa María (1351-1435) ${ }^{20}$, se ocupó de la instrucción de Juan II, ejerció de consejero suyo y fue canciller de Castilla tras la muerte de López de Ayala ${ }^{21}$. Para educar al joven rey, escribió una obra que se conoce como las Edades del mundo ${ }^{22}$ y que influyó en el formato historiográfico elegido por su hijo: una historia de carácter general, a pesar de que el cultivo de este tipo de historiografía llevaba en desuso desde

${ }^{15}$ Cfr. Robert Brian Tate, Ensayos sobre la historiografia peninsular del siglo XV, Madrid, Gredos, 1970, p. 107.

${ }^{16} C f r$. A. López Fonseca y J. M. Ruiz Vila, Rodrigo..., ed. cit., p. 20.

${ }^{17}$ Una prueba clara de ello es que la Oratio 12 constituye casi todo el capítulo 13 del Libellus.

${ }^{18}$ Conviene tener presente que el interés de Pío II por la geografía venía de lejos, pues no solo escribió unos Comentarii sobre su tiempo, sino que durante su juventud escribió obras de geografía, entre las que destacan De Europa (1458) y De Asia (1461), reunidas ambas bajo el título Historiarum rerum ubique gestarum.

${ }^{19}$ Acerca de la Breuis historie Hispanie, vid. G. Alvar Nuño, Estudio..., ed. cit., pp. 77-86.

${ }^{20}$ Merece un pequeño comentario el hecho de que la conversión de Pablo García de Santa María al cristianismo deparó a su familia una ascenso fulgurante en su estatus social. La carrera eclesiástica de Pablo García de Santa María comenzó al amparo de Benedicto XIII, a quien conoció cuando cursaba estudios de teología en París; fue nuncio del antipapa en Castilla, lo que le abrió las puertas de la corte regia: llegó a ser capellán de la corte, consejero real y ayo del príncipe heredero, por lo que la lealtad a la corona hubo de ser total. Esto facilitó sobremanera el ascenso de su hijo Alfonso de Cartagena (cfr. Fernández Gallardo, Alonso..., ed. cit., pp. 28-33) que, a su vez, facilitó la promoción política de Sánchez de Arévalo (Susana Guijarro González, Jerarquía ..., ed. cit., pp. 295-296). Así se granjeaba las lealtades la dinastía Trastámara.

${ }^{21} C f r$. Fernando Rubio, «Don Juan II de Castilla y el movimiento humanístico de su reinado», en $L a$ ciudad de Dios, 168 (1955), pp. 55-100, pp. 60-61.

${ }^{22}$ De acuerdo con Luis Fernández Gallardo, «La obra historiográfica de dos conversos ilustres, don Pablo de Santamaría y don Alonso de Cartagena», en Espacio, tiempo y forma. Serie 3, Historia Medieval 6 (1993), pp. 249-286, pp. 257-258, las Edades del mundo, que se trataba de una obra de historia destinada a educar al futuro rey Juan II de Castilla, fueron escritas en castellano y en verso para estimular su finalidad didáctica. 
finales del siglo XIII; a su vez, Alfonso de Cartagena debió influir en Sánchez de Arévalo y en Joan Margarit ${ }^{23}$. Tanto Alfonso de Cartagena como Sánchez de Arévalo y Joan Margarit fueron grandes diplomáticos y, en consecuencia, su producción historiográfica fue redactada en latín. Las razones de esta elección han sido explicadas por Cuart ${ }^{24}$ :

Se trata de obras uno de cuyos objetivos es el de destacar y aun defender las excelencias y el papel preponderante que había tenido Hispania desde la Antigüedad hasta el presente frente a aquellos que, sintiéndose superiores culturalmente pero sometidos políticamente, hablaban con excesiva frecuencia de la barbarie hispanica. Por lo tanto, se trataba de oponer, en buen latín, una Hispania fértil, culta, heredera de las grandezas de Roma, políticamente fuerte y con un amplio plantel de personalidades que desde la misma Antigüedad al tiempo actual habían brillado en Europa, al exclusivismo italiano que quería recaer estas aportaciones únicamente en sus propios logros. Se trataba, en definitiva, de una oposición Hispania/Italia que conllevaba tomar como campo de acción la totalidad de la Península Ibérica, la antigua Hispania, tal como los italianos hablaban de la antigua Italia, por mucho que ambos territorios se encontrasen en la actualidad divididos políticamente.

\section{La Anacephaleosis de Alfonso de Cartagena y la Compendiosa historia} Hispanica de Rodrigo Sánchez de Arévalo fueron terminadas el año mismo de la muerte de cada uno, 1456 en el caso de Cartagena y 1470 en el caso de Arévalo. En ese sentido, cumplieron al pie de la letra los preceptos que enunciaba Cicerón en el De oratore. El primero, el de una vida ejemplar: ambos escritores habían destacado en la práctica retórica gracias a su cargo de oratores de la corona de Castilla, actividad a la que Cicerón había consagrado su vida entera (De orat. $1,1,1)$ :

Ac fuit cum mihi quoque initium requiescendi atque animum ad utriusque nostrum praeclara studia referendi fore iustum et prope ab omnibus concessum arbitrarer, si infinitus forensium rerum labor et ambitionis occupatio decursu honorum, etiam aetatis flexu constitisset ${ }^{25}$.

${ }^{23}$ Ibidem, p. 259.

${ }^{24}$ Vid. Baltasar Cuart, «La larga marcha hacia las historias de España en el siglo XvI», en La construcción de las historias de España, ed. de Ricardo García Cárcel, Madrid, Marcial Pons, pp. 45-126, p. 64.

${ }^{25}$ Trad.: Y sucedió que pensaba que sería justo y permitido por casi todos que me llegara a mí también el momento de descansar, así como de reconducir mi ánimo a las hermosas aficiones de ambos, en caso de que hubiese cesado el incansable ajetreo del foro y la dedicación por el final de mi carrera y, además, debido a la caída de los años. 
En segundo lugar, habían tenido que dominar varios saberes, entre los que se contaban, por supuesto, el derecho y la historia (De orat. 1, 5, 17): «Tenenda praeterea est omnis antiquitas exemplorum vis, neque legum ac iuris civilis scientia neglegenda est $\rangle^{26}$. La vida de ellos había transcurrido a imagen y semejanza del verdadero orador que predica el De oratore $(1,1,20)$ : «Ac mea quidem sententia nemo poterit esse omni laude cumulatus orator, nisi erit omnium rerum magnarum atque artium scientiam consecutus, etenim ex rerum cognitione efflorescat et redundet oportet oratio ${ }^{27} \gg$.

Por último, ni que decir tiene que cumplieron con el deber de escribir historia, pues esta fue definida por Cicerón como munus maxime oratorium $\mathrm{y}$, por tanto, la cumbre en la carrera de todo orador, de ahí que cultivaran el género en los últimos años de vida, tras haber acumulado una enorme experiencia internacional (De orat. $2,15,62-63$ ):

Sed illuc redeo: videtisne quantum munus sit oratoris historia? Haud scio an flumine orationis et varietate maximum; neque eam reperio usquam separatim instructam rhetorum praeceptis; sita sunt enim ante oculos. Nam quis nescit primam esse historiae legem, ne quid falsi dicere audeat? Deinde ne quid veri non audeat? Ne quae suspicio gratiae sit in scribendo? Ne quae simultatis? Haec scilicet fundamenta nota sunt omnibus, ipsa autem exaedificatio posita est in rebus et verbis: rerum ratio ordinem temporum desiderat, regionum descriptionem; vult etiam, quoniam in rebus magnis memoriaque dignis consilia primum, deinde acta, postea eventus exspectentur, et de consiliis significari quid scriptor probet et in rebus gestis declarari non solum quid actum aut dictum sit, sed etiam quo modo, et cum de eventu dicatur, ut causae explicentur omnes vel casus vel sapientiae vel temeritatis hominumque ipsorum non solum res gestae, sed etiam qui fama ac nomine excellant, de cuiusque vita atque natura ${ }^{28}$.

${ }^{26}$ Trad.: Hay que dominar, por lo demás, todo el pasado y el vigor de sus ejemplos, y no hay que descuidar el conocimiento de las leyes y del derecho civil.

${ }^{27}$ Trad.: Y, en mi opinión, nadie podrá ser un orador colmado de todo tipo de elogio a no ser que haya logrado una sabiduría en todos los grandes asuntos y artes, pues conviene que un discurso florezca y rebose por el conocimiento de las cosas.

${ }^{28}$ Trad.: Pero vuelvo a ello: ¿véis cuánta actividad de orador hay en la historia? No sé si la mayor, debido al fluir del discurso y a la variedad; y no la encuentro tratada por separado de los preceptos de la retórica; en efecto, saltan a la vista. Pues ¿quién desconoce que la primera ley de la histora es que no hay que atreverse a decir algo falso? ¿Y, a continuación, que hay que atreverse con la verdad? ¿Que no haya sospecha de simpatía al escribir? ¿Ni de enemistad? Por supuesto, estos fundamentos son conocidos por todos, esta misma estructura ha sido dispuesta en los hechos y en las palabras: el desarrollo de los hechos necesita de un orden temporal, de una descripción de los lugares; además, puesto que se espera de los hechos que son dignos de ser recordados primero los consejos, luego los actos, y por último las consecuencias, exige que, en relación a los consejos, se indique qué aprueba el escritor, y, en relación a los sucesos acaecidos, que se declare no solo qué se hizo o se dijo, sino también de qué manera, y cuando se hable de la consecuencia, que se expliquen todas las causas debidas o al azar, o la sabiduría o la temeridad, 
Las citas a Cicerón no son fruto de la casualidad. En efecto, Alfonso de Cartagena, entre cuyos intereses se contaban la filosofía moral, la gramática y retórica latinas ${ }^{29}$, llevó a cabo la traducción del De inuentione de Cicerón al castellano bajo el nombre de Rethórica de Tulio M. Cicerón, que según Morrás ${ }^{30}$ comenzó durante su etapa como diplomático de Juan II ante el rey de Portugal y terminó en torno al año $1431^{31}$. También en torno a estos años, por cierto, tradujo Enrique de Villena la Rhetorica ad Herennium. Ambas versiones eran pioneras en Europa. El aumento del interés por la retórica en la Castilla de la primera mitad del siglo xv es evidente ${ }^{32}$, de otro modo no se puede explicar la importancia que Cartagena concedió a los studia humanitatis $^{33}$. La preocupación por la educación constituyó la base de su labor traductora (de obras ciceronianas, pero también de Séneca), centrada en la moral, la política y la retórica, es decir, en las artes del buen gobierno ${ }^{34}$; sin

y no solo las acciones llevadas a cabo por los propios protagonistas, sino también quiénes sobresalen por su fama o por su nombre, o debido a la vida y carácter de cada uno.

${ }^{29}$ Cfr. Cristina Martínez Gómez, Estudio, edición crítica y traducción del Memoriale Virtutum de Alfonso de Cartagena, Madrid, Universidad Complutense, 2015, Tesis Doctoral, p. 17.

${ }^{30} \mathrm{Cfr}$. María Morrás, «Repertorio de obras, manuscritos y documentos de Alfonso de Cartagena ( $c a$. 1384-1456)», en Boletín bibliográfico de la Asociación hispánica de literatura medieval, 5 (1991), pp. 215-248, p. 221.

${ }^{31}$ Acerca de la actividad traductora en Castilla a lo largo del s. xv, vid. Peter Russel, Traducciones y traductores en la Península ibérica (1400-1550), Bellaterra, Universidad Autónoma de Barcelona, 1985; José Francisco Ruiz Casanova, Aproximación a una Historia de la Traducción en España, Madrid, Cátedra, 2000, pp. 80-130; Tomás González Rolán y Antonio López Fonseca, Traducción y elementos paratextuales: los prólogos a las versiones castellanas de textos latinos en el siglo XV. Introducción, edición general y estudio, Madrid, Escolar y Mayo, 2014; Luis Fernández Gallardo y Teresa Jiménez Calvente, El Duodenarium (c. 1442) de Alfonso de Cartagena. Cultura castellana y letras latinas en un proyecto inconcluso, Córdoba, Almuzara, 2015, pp. 36-42.

${ }^{32}$ Así y todo, son válidas las observaciones de María Morrás, «Sic et non: En torno a Alfonso de Cartagena y los studia humanitatis», en Euphrosyne, 23 (1995), pp. 333-346, pp. 338-339, en cuanto a la evolución de la actitud de Cartagena respecto a la retórica. Conviene señalar que era capaz de adaptar su discurso a las circunstancias, de modo que su Discurso sobre la precedencia de Castilla sobre Inglaterra (1435) seguía la preceptiva escolástica, pues al pronunciarlo hablaba como jurista ante el Concilio de Basilea, y sin embargo en las Allegationes super conquistam insularaum Canarie (1437), Cartagena compuso su oratio de acuerdo con las reglas forenses descritas por Cicerón (De inu. 1, 14, 19), pues en esta ocasión hablaba como dictator, es decir, como político (ibídem, pp. 342-344). Jeremy N. H. Lawrance, Un episodio del proto-humanismo español. Tres opúsculos de Nuño de Guzmán y Giannozzo Manetti, Salamanca, Diputación Provincial, 1989, pp. 10-14, ofrece un comentario acerca del aumento del florecimiento de la oratoria castellana del Cuatrocientos que va íntimamente asociada, como él mismo señala (ibídem, p. 12), a la práctica de la actividad política.

${ }^{33}$ Acerca del conocimiento y actitud de Cartagena para con los studia humanitatis, vid. Luis Fernández Gallardo, «En torno a los studia humanitatis en la Castilla del Cuatrocientos. Alonso de Cartagena y los autores antiguos», en En la España Medieval, 22 (1999), pp. 213-246.

${ }^{34}$ Acerca de Cartagena y la traducción, vid. Ottavio di Camillo, «Humanism in Spain», en Renaissance Humanism. Foundation, Forms and Legacy. Volume 2. Humanism beyond Italy, ed. de Albert Rabil Jr. Filadelfia, Philadelphia University Press, 1988 pp. 55-108, pp. 76-81; Luis Fernández Gallardo, En torno ..., ed. cit., pp. 215-225; Luis Fernández Gallardo, «Alonso de Cartagena y el Humanismo», en La Corónica, 31:1 
embargo, a diferencia de los humanistas más exaltados, él percibió los studia humanitatis como complementarios -y no opuestos-a los studia scolastici ${ }^{35}$. La revalorización del ars loquendi en Castilla se debió a una situación similar a la de la Península Itálica de aquella época, como apuntó Di Camillo ${ }^{36}$. Una de las causas fue de carácter doméstico y consistió, lisa y llanamente, en la necesidad de proporcionar una mejor educación a los letrados y los secretarios de las cortes y, a continuación, a los miembros de la nobleza, arrastrados acaso por la importancia que concedió a las letras la monarquía Trastámara ${ }^{37}$. La otra causa, externa, vino dada por el contacto de los diplomáticos castellanos con homólogos extranjeros -especialmente italianos- durante diferentes misiones de política exterior, en las que tanto Cartagena como Sánchez de Arévalo jugaron un papel muy destacado, como se ha intentado demostrar.

Este último, aunque no llevó a cabo traducción alguna de clásicos latinos ni dejó ninguna obra escrita en la que abordara la importancia de la retórica, estudió sin embargo en Salamanca en un momento en que se habían consolidado unas reformas educativas que concedían gran importancia a la enseñanza de la retórica ${ }^{38}$, y eso se plasmó en sus discursos y en su Compendiosa historia Hispanica, mucho más rica, colorida y amplia que cualquiera de las historias generales que la precedieron. Se empezaba a aplicar el princpio catoniano del uir bonus dicendi peritus.

(2008), pp. 1-41, pp. 2-18; C. Martínez Gómez, Estudio..., ed. cit., pp. 47-48. Elisa Borsari, «Leonardo Bruni y el discurso traductológico», en eHumanista, 28 (2014), pp. 355-368, ha subrayado la relación íntima del trabajo de traducción con la práctica del Humanismo cívico y el cultivo de los studia humanitatis.

${ }^{35}$ Cfr. M. Morrás, «Sic...», art. cit., pp. 344-346. La preocupación por los studia humanitatis de Alfonso de Cartagena es paralela a la de Leonardo Bruni, quien reflexiona sobre ellos en su De studiis et litteris tractatulus ad Baptistam Malatestam, según la opinión de Maury D. Feld, «Sweynheym and Pannartz, Cardinal Bessarion, Neoplatonism: Renaissance Humanism and Two Early Printers' Choice Texts», en Harvard Library Bulletin, 30 (1982), pp. 282-335, pp. 290-291. No está de más recordar que a ambos intelectuales les unió una cierta amistad y mantuvieron una relación epistolar, fruto de la atracción que el castellano sintió por el pensamiento de Bruni.

${ }^{36}$ Cfr. Ottavio di Camillo, El humanismo castellano del siglo XV, Valencia, Fernando Torres, 1976, pp. 49-51.

${ }^{37}$ La propia figura del rey Juan II parece clave en el despertar del interés por la cultura entre la nobleza castellana, debido a que su pasión personal por las letras, la música, la filosofía moral y la historia -y el mecenazgo que ejerció con la cultura, de lo que se ha ofrecido alguna pincelada en estas páginas- debió causar moda (cfr. Cristina Martínez Gómez, Estudio..., ed. cit., pp. 37-38).

${ }^{38}$ O. Di Camillo, El humanismo..., ed. cit., pp. 45-47, ofrece un panorama amplio del paso de la escolástica a la retórica humanística en ámbito castellano. No hay que olvidar un dato importante al respecto: el cardenal Gil de Albornoz había creado el Colegio de san Clemente de Bolonia, conocido como Colegio de los Españoles, en 1367 ( $c f r$. O. Di Camillo, Humanism..., ed. cit., p. 64); Vicente Ángel Álvarez Palenzuela, («Innovación intelectual: de la escolástica al humanismo», en Historia del cristianismo. 2. El mundo medieval, ed. de Emilio Mitre Fernández, Granada, Trotta, 2004, pp. 575-630, p. 606), por su parte, indica que la creación de Colegios a lo largo de los siglos XIV y XV (el de Bolonia entre ellos) pretendía la formación de estudiantes bien dotados, independientemente de su extracto social, para ejercer de letrados para el papado y las monarquías; estos acabaron creando auténticas élites intelectuales. 


\section{La Compendiosa historia Hispanica frente al humanismo italiano}

Uno de los elogios más certeros con que se ha obsequiado a Sánchez de Arévalo fue el que Tate ${ }^{39}$ le dedicó al decir que era «capaz de lanzar un opúsculo bien documentado en pleno vuelo polémico». Si bien es cierto que la Compendiosa no es ni mucho menos un opúsculo, se trata sin embargo de un texto con un programa político muy claro ${ }^{40} \mathrm{y}$, en ese sentido, fue escrita para defender los intereses castellanos en los ambientes intelectuales de la Península Itálica ${ }^{41}$. Debido a su papel como embajador de la corona castellana, Sánchez de Arévalo empleó el latín como código lingüístico para casi toda su producción escrita. La Compendiosa, dijo Tate ${ }^{42}$, «goza de la doble distinción de ser la primera historia importante de España desde la Historia Gothica de Jiménez de Rada y la primera historia de España de cualquier tipo que se imprimió, unos veinte años antes de la aparición del incunable De laudibus Hispaniae libri VII de Lucio Marineo Sículo» ${ }^{43}$; por ello, el uso del latín fue una decisión premeditada y, huelga decirlo, acertada en relación al contexto internacional en que se desenvolvía su autor. Lo mismo había sucedido con la Anacephaleosis de Alfonso de Cartagena. Este asunto ha sido discutido en varios lugares ${ }^{44}$, y hay acuerdo en que la eficacia propagandística de una

${ }^{39}$ Vid. R. Brian Tate, Ensayos..., ed. cit., Madrid, Gredos, 1970, p. 75.

${ }^{40}$ Respecto a la intencionalidad política de la Compendiosa historia Hispanica, vid. Luis Fernández Gallardo, «La Historia Hispanica de Rodrigo Sánchez de Arévalo: Propaganda enriqueña y actitudes antihumanistas», en Anthologica Annua, 48-49 (2001-02), pp. 275-337; y el excelente artículo de Biörn Tjällén, «Political Thought and Politicak Myth in Late Medieval National Histories: Rodrigo Sánchez de Arévalo († 1470)», en The Medieval Chronicle VIII, ed. de Erik Kooper, Sjoerd Level, Amsterdam, Rodopi, 2013, pp. 273-288.

${ }^{41}$ Prueba de la importancia que tuvo la Compendiosa en los años subsiguientes a su publicación es una traducción anónima de la obra al italiano (el ms. 0411 de la Biblioteca Histórica de la Universidad de Valencia), que perteneció a Fernando de Aragón, duque de Calabria, y que regresó con él en 1527 con motivo de su boda con Germana de Foix, la viuda de Fernando el Católico. El único estudio existente de este códice a día de hoy es el de Bertomeu Masià, «La traducción italiana de la Compendiosa historia Hispanica de Rodrigo Sánchez de Arévalo», en Campus Stellae. Haciendo camino en la investigación literaria. Tomo I, ed. de Dolores Fernández López y Fernando Rodríguez-Gallego, 2006, pp. 124-132, de donde recojo la información. Este volumen pertenecía a la gran biblioteca familiar que habían amasado los reyes de Nápoles, Alfonso el Magnánimo y Ferrante de Aragón. La obra se debió traducir a finales del siglo XV y, según se desprende de los rasgos lingüísticos de escritura, el copista debió ser originario del centro-sur de la Península Itálica. Estos datos apuntan invariablemente a que la obra fue conocida, además de en Roma, en los círculos eruditos napolitanos.

${ }^{42}$ Vid. R. Brian Tate, Ensayos..., ed. cit., p. 71.

${ }^{43}$ Sobre la caída en desuso del latín como lengua de cultura en Castilla, vid. Benito Sánchez Alonso, Historia de la historiografia española, Madrid, CSIC, 1947, vol. I, p. 207.

${ }^{44}$ B. Sánchez Alonso, Historia..., ed. cit., p. 207; Ángel Gómez Moreno, España y la Italia de los humanistas. Primeros ecos, Madrid, Gredos, 1994, pp. 109-120; Tomás González Rolán, Ángel Moreno Hernández y Pilar Saquero Suárez-Somonte, Humanismo y teoría de la traducción en España e Italia en la primera mitad del siglo XV, Madrid, Ed. Clásicas, 2000, pp. 139-140; L. Fernández Gallardo, Alonso..., 
obra histórica sobre Castilla que debía ser difundida en ambientes europeos pasaba por ser escrita en latín. Sin embargo, a pesar de que Tate y Fernández Gallardo $^{45}$ defendieron que el uso de la lengua latina no guardaba relación con una influencia italiana, sí parece esta elección se puede considerar una muestra de la profunda huella que dejaron los humanistas italianos en Alfonso de Cartagena y en Rodrigo Sánchez de Arévalo ${ }^{46}$.

Esta faceta beligerante que caracterizó a Arévalo se deja ver desde el mismísimo Prólogo de la Compendiosa, prólogo que aprovechó para incorporarse a un acalorado debate entre Leonardo Bruni y Alfonso de Cartagena respecto a los criterios de traducción que empleó aquel en su versión al latín de la Ética de Aristóteles ${ }^{47}$. Bruni sabía que su traducción iba a resultar polémica y, en efecto, Cartagena defendió ante el italiano la de Roberto Grosseteste, que le parecía mejor en diversos aspectos, lo que desencadenó la discusión. Arévalo conoció de primera mano el enfrentamiento que mantuvieron su maestro y Bruni, ya que hizo de mensajero de Pier Candido Decembrio después de que el italiano decidiera ordenar toda la discusión bajo el nombre de Declamationum libri y regalársela a Alfonso de Cartagena ${ }^{48}$. Como parte de la argumentación de esta controversia, Leonardo Bruni había llegado a asegurar lo siguiente (Contr. Alph. 3, 72-79, pp. 270-272) ${ }^{49}$ :

Illud etiam leue, quod Italicos statim calamum arripere inquit, quod otiosi sint: Hispanos uero, quod regia curia sint occupati, calamo uacare non posse. Quasi uero Itali non curiam habeant Romanam multo certe maiorem, quam sit regia, et infinitas publicarum priuatarumque rerum occupationes. Nec sane consentaneum est, ut in extremo mundi angulo plus humanarum occupationum sit, quam in medio $^{50}$.

ed. cit., pp. 289-290; Guillermo Alvar Nuño, «Rodrigo Sánchez de Arévalo y la historiografía en el siglo XV», en Ardua cernebant iuuenes. Estudios Clásicos. Anejo 2 (2014), pp. 223-230, pp 224-225.

${ }^{45}$ Cfr. R. Brian Tate, Ensayos..., ed. cit., p. 71; L. Fernández Gallardo, Alonso..., cit., p. 289.

${ }^{46}$ Cfr. B. Sánchez Alonso, Historia ..., ed. cit., p. 319; T. González Rolán, Á. Moreno Hernández y P. Saquero Suárez-Somonte, Humanismo..., ed. cit., p. 140.

${ }^{47}$ El primer investigador que sacó a la luz la polémica fue Alexander Birkenmaier, «Der Streit des Alonso von Cartagena mit Leonardo Bruni Aretino», en Beiträge zur Geschichte der Philosophie des Mittelalters, 20:5 (1922), 129-210. El hermoso desarrollo de esta disputa intelectual, que se puede seguir en T. González Rolán, Á. Moreno Hernández y P. Saquero Suárez-Somonte, Humanismo..., cit., pp. 95103, se hizo con un moderador, el arzobispo de Milán Francesco Pizzolpasso, y tuvo como resultado una declaración llena de orgullo por parte de Cartagena, la de que había conseguido una amistad sincera con sus dos rivales, Bruni y Decembrio.

${ }^{48}$ Ibídem, pp. 82 y ss., especialmente pp. 87-88.

${ }^{49}$ Sigo la edición de T. González Rolán, Á. Moreno Hernández y P. Saquero Suárez-Somonte, Humanismo..., ed. cit.

${ }^{50}$ Trad.: Otra cosa también ligera: que los italianos toman pronto el cálamo, que permanecen desocupados: en cambio los hispanos, puesto que están ocupados en la curia regia, no tienen tiempo para el 
Alfonso de Cartagena se molestó con esta aseveración pues, en una carta que escribió Leonardo Bruni a Francesco Pizzolpasso, hizo referencias a ese pasaje de la conversación (Contr. Alph. 5, 260-268, p. 304):

Reprehendit, quia scriptum fuerit a me de Hispania non esse consentaneuum, ut in extremo mundi angulo plus humanarum occupationum sit, quam in medio; asserit enim mundum non habere angulos ac me redarguit quasi geometriae ignarum. In quo longe aberrat. Mundus enim permultos habet angulos; tot enim habet, quot in mundo sunt ${ }^{51}$.

Por lo demás, Leonardo Burni insitió de manera cerril en el desprecio a Hispania (Contr. Alph. 5, 296-303, pp. 306-308):

Equidem mihi satis multa legisse de Hispania uideor situmque et magnitudinem eius portusque tam in hoc Mediterraneo, quam in Oceano mari existentes non, ut Alphonsus putat, ignoro. Magna quidem illa uideri potest, si ad minores prouincias comparetur; sin autem ad magnitudinem orbis terrarum, perparua reperietur. Alphonsus autem noster, sum sit geometra et mathematicus, nimio patriae detinetur amore; itaque magnam putat, quae exigua est ${ }^{52}$.

Con todo, quiso matizar sus palabras ante Pizzolpasso (Contr. Alph. 5, 316321) al explicarle por carta que Cartagena no tenía por qué sentirse ofendido de que calificara a Hispania de extremam mundi regionem, pues la tierra en su totalidad era estrecha. A la luz de estos comentarios se puede entender que las obras historiográficas de Alfonso de Cartagena primero, y de Sánchez de Arévalo después, intentaran colmar un vacío. En el caso de la Anacephaleosis, ya se ha dicho que tuvo un éxito relativamente escaso. Mejor suerte corrió la Compendiosa, y quizás ello explique la amplitud del proyecto. El hecho de encontrarse en Roma trabajando para el papado debió ser un acicate más que propició que Sánchez de Arévalo tuviera unas circunstancias de trabajo más

cálamo. Como si los italianos no tuvieran una curia romana sin duda mucho mayor que la regia, e infinitas ocupaciones en asuntos tanto públicos como privados. No es muy lógico que haya más ocupaciones propias de hombres en el último rincón del mundo que en el centro.

${ }^{51}$ Trad.: Me critica porque yo escribí de Hispania que no es lógico que haya más ocupación en el último rincón del mundo que en el centro; asegura que el mundo no tiene rincones y me regaña como si yo fuera lego en geometría. En esto se equivoca por completo. El mundo, en efecto, tiene muchísimos rincones; es decir, tiene tantos cuantos hay en el mundo.

${ }^{52}$ Trad.: Me parece, sin duda, que he leído mucho sobre Hispania, lo suficiente; y no ignoro, como piensa Alfonso, su ubicación, su grandeza y los puertos tanto en este Mediterráneo como en el mar Océano. Sin duda, puede parecer grande si se compara con provincias menores, en cambio, si se compara a la grandeza del orbe terrestre, resultará muy pequeña. Nuestro Alfonso, por muy geómetra y matemático que sea, se obceca en un amor desmesurado a la patria; así pues, piensa que es grande cuando es pequeña. 
favorables. Su primer objetivo fue defender Hispania de las acusaciones de Leonardo Bruni, y lo hizo -conviene insistir en ello-, argumentando a la manera de los humanistas, es decir, a través de la cita a autores clásicos. Para ello, presentó el meollo de la Controuersia Alphonsiana de manera prudente, pues eliminó cualquier referencia concreta a sus protagonistas (Comp. prol., 9-16) ${ }^{53}$ :

Falluntur plurimum qui Hispaniarum laudes, patrie situm, gentis religionem et cultum, atque uirtutes et studia, bellorum quoque uictorias, aut nolunt aut scire negligunt. Idque, ut arbitror, ob scriptorum inopiam contigisse putandum est: quemadmodum de gestis Romanorum Sallustius in Catilinaria conqueritur. Inuidet enim Atheniensibus, quod res suas scribentium industria longe illustriores in toto orbe quam fuerint referantur. Nec aliter de rebus Hispanicis dici potest ${ }^{54}$.

A continuación, enumeró las críticas vertidas contra Hispania, cuya mejor defensa se hallaba, en efecto, en los propios autores clásicos, no solo latinos, sino también griegos - tan del gusto de Bruni-, como se hace patente a lo largo de la primera parte de la obra, en que la cita a unos y otros es constante (Comp. prol., 25-31):

Ceterum nonnulli Hispanas res legere dedignantur, eo, ut puto, errore ducti quo nonnulli bonarum partium ac rerum inexperti, quod in angulo mundi, ut aiunt, Hispania sita esse uideatur, contendunt, atque extra orbem posita, ut eorum uerbis utar, ab orbis gloria aliena uideatur. Longe aliter sapientes cosmographi sensere, qui orbem descripturi, ab Hispania tanquam a principali orbis porta incepere ${ }^{55}$.

${ }^{53}$ De aquí en adelante, convendrá tener muy presente la siguiente reflexión de Carlos Heusch, «Protohumanisme et élites lettrées dans la Castille du $\mathrm{XV}^{\mathrm{e}}$ siècle», en Modèles et circulation des savoirs en Méditerranée occidentale (XII $-X V^{e}$ siècles), ed. de Patrick Gilli, Montpellier, Presses Universitaires de la Méditerranée, 2008, pp. 303-331, p. 310: «Les échanges avec la "nouvelle" culture italienne de l'époque ont, certes, produit, chez quelques individualités spécialement réceptives à telles idées, une véritable prise de conscience de l'importance du passé et de ses manifestations culturelles, mais cette prise de conscience ne pouvait impliquer un mouvement calqué sur celui des Italiens dès lors que des différences fondamentales idéologiques et sociales séparaient les uns et les autres».

${ }^{54}$ Trad.: Se equivocan muchísimo quienes no quieren o no se preocupan por conocer los elogios de las Hispanias, el emplazamiento de esa patria, la devoción y costumbre de su gente y sus virtudes y desvelos; también sus victorias en la guerra. Y hay que pensar, según me parece, que ello ha concernido a la escasez de escritores; del mismo modo se queja Salustio acerca de las gestas de los romanos en la Conjuración de Catilina. Envidia, en efecto, a los atenienses, porque sus hazañas son relatadas en todo el orbe gracias a la industria de sus escritores, de modo mucho más ilustre de lo que fueron. Y no se puede decir otra cosa acerca de las hazañas hispánicas.

${ }^{55}$ Trad.: Por lo demás, algunos desdeñan leer las hazañas hispanas, conducidos a ese desatino, según pienso, porque algunos, desconocedores de sus regiones y asuntos, se empeñan en que parezca que Hispania está situada, según dicen, en un rincón del mundo y, emplazada fuera del orbe, por usar sus mismas palabras, 
A decir del propio Arévalo, fue el rey quien le encomendó la redacción de la obra; la causa parece hallarse en la Controuersia Alphonsiana, de la que debió tener conocimiento el rey, según se desprende del texto (Comp. prol., 37-45):

Vt igitur huiusmodi hominum error tanto apertius a mentibus sensatorum exulet quanto est a ueritate remotior, mandauit mihi Serenitas Tua, que totius Orientis simul et Mediterranee ac Septentrionis regionum situm descriptionem et principatus preclarasque res sic mente tenet, ac si pedibus oculisque illa omnia peragrando conspexisset, ut nostram Hispaniam, immo Tuam, que Occidentis plagam tenet ad aliorum potius quam tuam instructionem breuissime describerem ${ }^{56}$.

No debe sorprender que Arévalo dedicara la obra a Enrique IV pues, como mostró Tjällén ${ }^{57}$, Arévalo fue un defensor acérrimo de la monarquía castellana -al igual que lo fue de la monarquía papal-, para lo cual redactó tanto obras políticas (valgan de ejemplo De monarchia orbis y De origina acdifferentia principatus imperialis et regalis) como la propia Compendiosa, en la que se presentó la continuidad de la realeza castellana desde sus supuestos orígenes godos. Estas necesidades prueban que la decisión de volver al latín como vehículo de expresión en lugar del castellano obedece a una motivación política $^{58}$, así como el hecho de defender la dignidad e importancia histórica de la Península Ibérica -o, mejor aún, de Castilla- en tierra itálica. Y, si bien fue de manera indirecta, Leonardo Bruni puede considerarse el causante del retorno al latín como lengua para la historiografía en el siglo Xv peninsular, prueba, una más, de la permeabilidad castellana a la influencia humanista. Sin entrar en más detalles, la finalidad propagandística de la Compendiosa historia Hispanica tenía dos objetivos principales: la reafirmación de la

parezca ajena a la gloria del orbe. Hace mucho los sabios cosmógrafos lo percibieron de manera diferente, los cuales, para describir el orbe, empezaron por Hispania igual que si fuera la puerta principal del orbe.

${ }^{56}$ Trad.: Así pues, para que el error de este tipo de hombres se destierre de mentes sensatas de forma tan manifiesta cuanto dista de la verdad, me ha mandado Su Serenidad, que sí tiene en mente la ubicación, la descripción, el gobierno y las ilustres hazañas de las regiones de todo el Oriente junto con las del Mediterráneo y las del Septentrión como si las hubiera contemplado todas ellas recorriéndolas con pies y ojos, que describiera la Hispania nuestra, más bien Vuestra, la cual ocupa la extensión de Occidente, para instrucción de otros más que para la Vuestra.

${ }^{57}$ Biörn Tjällén, Political ..., ed. cit., pp. 275-276.

${ }^{58}$ Esta decisión tuvo un éxito notable, habida cuenta de la nómina de historiadores al servicio de la corona castellana que escribieron en latín de Arévalo en adelante ( $C f r$. Teresa Jiménez Calvente, «Teoría historiográfica a comienzos del siglo XVI», en Imágenes Históricas de Felipe II, ed. de Alfredo Alvar Ezquerra, Madrid, Centro de Estudios Cervantinos, 2000, pp. 197-215, pp. 198-202) que convivieron junto a los que elaboraron su obra en lengua vernácula. 
monarquía por medio de una literatura bajo su control, y la justificación de las aspiraciones internacionales de Castilla.

\section{De Isidoro a Alfonso de Cartagena: El lugar de la Compendiosa histo- ria dentro de la historiografía peninsular castellana}

La Compendiosa historia Hispanica, como cualquier otra producción escrita, muestra una relación de dependencia (formal y de contenido) tanto con respecto a la literatura precedente como con respecto a la literatura contemporánea. Si hay que hacer caso al propio Sánchez de Arévalo, él pretende imitar y continuar la obra del arzobispo de Toledo Rodrigo Jiménez de Rada, quien escribió bajo el reinado de Fernando III una Historia de rebus Hispanie o Historia Gothica, punto de referencia para gran parte de la Compendiosa historia Hispanica. En ella narraba la historia de la Península desde lo que él consideraba sus primeros pobladores hasta el año de 1243. En efecto, la obra del Toledano sirve no solo para ayudar a concebir la arquitectura de la Compendiosa, sino que se trata también de uno de los grandes ovillos del cesto de donde Arévalo extrae el hilo narrativo de su obra histórica. Se trata, por tanto, de un modelo buscado, y es buscado, además, de manera explícita. En efecto, en el prólogo general a la Compendiosa se puede leer (Comp. prol., 105-116):

In quarta parte, continuans Roderici Toletani historiam, incipiam a dicto Fernando, in quo ille scribendi finem dedit; deinde sequentium post illum in Hispania regnantium successsiones clarioraque gesta usque ad hos nostros dies in quos fines seculi peruenerunt, quibus Tua Excellentissima Maiestas felicitanter regnat; demum que predictorum regum temporibus digna relatu fuere tam in Romana et apostolica sede quam imperio clarioraque exterorum illustrium uirorum et pulchra sapientum documenta breui et fideliter referam, ut quod unus Rodericus presul tam utiliter inchoauit, alius eiusdem nominis et professionis expleat, impari tamen sapientia et eloquio licet pari affectu ${ }^{59}$.

\footnotetext{
${ }^{59}$ Trad.: En la cuarta parte, dado que continuaré la historia de Rodrigo de Toledo, comenzaré por dicho Fernando, con el que él puso fin a su obra, después, con las sucesiones de quienes siguieron reinando tras él en Hispania y con sus gestas más luminosas hasta estos días nuestros adonde han llegado los fines de los siglos, en los que Su Excelentísima Majestad reina para dicha de todos; por último, referiré con brevedad y fidelidad las cosas que han sido dignas de relato tanto en la Sede Romana y Apostólica como en el Imperio durante los tiempos de los reyes que se hayan ido mencionando, así como los hechos más luminosos de ilustres varones extranjeros y las pulcras enseñanzas de los sabios, de modo que lo que un obispo Rodrigo empezó de manera tan útil, otro de igual nombre lo complete, acaso con desigual sapiencia y expresión, pero con cariño igual.
} 
En cuanto a la manera de escribir historia, es decir, en el aspecto puramente formal, Sánchez de Arévalo estructura su propia crónica según la influencia de Jiménez de Rada. Así, la divide en libros y capítulos, cada uno de ellos con su título correspondiende, de igual manera que hace el arzobispo toledano. A pesar de las similitudes, hay que señalar que la Compendiosa historia Hispanica se divide en cuatro libros, y no nueve como el De rebus Hispanie. De manera más concreta, la influencia del primer libro del De rebus Hispanie es parcial en el libro primero de la Compendiosa, pues coinciden solo en querer establecer una genealogía mítica desde los primeros pobladores de la Península (bíblicos, griegos y romanos) hasta la llegada de los godos. La presencia de Jiménez de Rada se deja sentir de manera intensa en el libro segundo de la Compendiosa y, sobre todo, en el tercero; de él extrae Arévalo una cantidad inagotable de material narrativo. El cuarto libro de la Compendiosa es una continuación de la Historia de rebus Hispanie, cuyo primer capítulo, dedicado a Alfonso X, continúa con la narración de la sucesión de reyes hispanos allí donde Jiménez de Rada concluyó su crónica (pues el último reinado que describe es el de Fernando III, padre de Alfonso X). No hay posibilidad de duda respecto a esta enorme dependencia textual, pues Arévalo mismo lo indica (Comp. IV prol., 18-26):

Demum historiam ipsam rerum Hispanicarum altius repetemus, pro eo maxime, quia prefati Roderici Toletani historia regum sequentium tempora non attigerit, sed solum in eodem Fernando iii narrationem clausit. Itaque agemus in hac quarta parte de xi regibus qui post Fernandum iii predictum in Hispania, Castella uidelicet et Legione regnarunt, atque in prouinciis eidem principatui subditis, et de eorundem regum genealogiis et successionibus ac claris gestis ${ }^{60}$.

Aún más íntima parece la relación formal de Arévalo con la Anacephaleosis de Alfonso de Cartagena, de 1456, pues también ella le sirve para dar forma a la estructura general de la obra, pero, además, le inspira al establecer la arquitectura interna de cada uno de los capítulos. Sin embargo, no hay mención alguna en toda la Compendiosa ni a Cartagena ni a su Anacephaleosis. Este silencio se puede deber a la proximidad temporal entre ambos

${ }^{60}$ Trad.: De hecho, revisaremos con más profundidad la historia de los asuntos hispánicos en sí misma, sobre todo por aquello de que la historia del mencionado Rodrigo el Toledano no se ocupó de los tiempos de los reyes posteriores, sino que terminó su narración justo en Fernando III. Así pues, en esta cuarta parte trataremos de los once reyes que reinaron después del mencionado Fernando III en Hispania, es decir, en Castilla y en León, y también en las provincias sometidas a su gobierno, y de las genealogías, sucesiones y gestas destacadas de esos reyes. 
autores y ha de considerarse, pues, como un mecanismo para distanciar la Compendiosa de otro de sus modelos principales que, por haber sido escrito menos de dos décadas antes, podría resultar conocido para los lectores más eruditos. Fernández Gallardo ${ }^{61}$ indica que el género de la obra de Cartagena, «como expresión de una voluntad de forma, condiciona la selección de contenidos y, asimismo, de las fuentes. El molde elegido por Alfonso de Cartagena para articular su visión del pasado hispano corresponde al más elemental de los géneros historiográficos, la genealogía». Con todo, matiza un poco más adelante ${ }^{62}$ que «la Anacephaleosis representa un testimonio expresivo de ese tránsito de la genealogía a la historia. Podríamos, por tanto, decir que el esquema, la estructura, es genealógica, en tanto que los contenidos son los sólitos de la cronística». La Compendiosa, en cambio, aun situándose dentro de estos parámetros, se encuentra más próxima, por extensión y complejidad, a la historiografía plenamente renacentista.

De acuerdo con Espinosa Fernández ${ }^{63}$, la Anacephaleosis consta de 94 capítulos divididos en dos libros. Los capítulos 1-44 hablan de los orígenes de la Península Ibérica hasta el rey don Rodrigo y la irrupción de los musulmanes, y del 45 al 94 se narran las vidas de los diferentes reyes castellanoleoneses hasta Enrique IV. De manera un poco más detallada, los capítulos 1 a 7 hablan de la ubicación geográfica de Hispania y de la historia primitiva de la Península, y del origen de los godos y su llegada a Hispania. Entre los capítulos 8 y 44 se hace una descripción de los reinados de los diferentes reyes godos desde Atanarico hasta don Rodrigo. Aquí acabaría el primer libro de la Anacephaleosis. Desde el capítulo 45 hasta el 94 se puede leer la narración de los reyes de Asturias, León y Castilla; Alfonso de Cartagena empieza con Pelayo y termina en Enrique IV, rey de Castilla cuando pone fin a su obra.

Así pues, Sánchez de Arévalo teje su Compendiosa historia Hispanica teniendo como modelo explícito a Jiménez de Rada y siguiendo la convención de época marcada por Cartagena, segundo ovillo en el cesto de su inspiración. Él decide dedicar la primera parte de su obra a hablar en profundidad de la geografía ibérica y hacer un elogio de todas las virtudes del territorio, así como a explicar el origen de los pueblos bárbaros, tal y como explica en el prólogo (Comp. prol., 78-92):

${ }^{61}$ Vid. L. Fernández Gallardo, La obra ..., ed. cit., p. 270

${ }^{62}$ Ibidem, p. 271.

${ }^{63}$ Cfr. Yolanda Espinosa Fernández, La Anacephaleosis de Alonso de Cartagena: edición, traducción, estudio, 3 vols., Madrid, Universidad Complutense, 1989, Tesis Doctoral, pp. 51 y ss. 
In prima quidem Hispanice aure salubritatem terreque feracitatem, auri argentique ac ceterorum metallorum et mineralium diuitias ac fecunditatem, gentis quoque religionem, fidem, amicitiam, humanitatem, strenuitatem; denique ac ceteras hominum et glebe Hispanie laudes et preconia breui interseram, situm rursus Hispaniarum illarumque descriptionem respectu ceterorum orbis climatum et regionum antiquitatem; denique principatus Hispanici regnorumque erectionem, sed et diuisionem et quando et quomodo et a quibus inceperunt ac in quo tandem regno Hispanie titulus resideat; rursus in ea parte Grecorum, Penorum ac Romanorum ad Hispanias ingressum, initium denique et originem principatus Gothorum, Astrogothorum, Vandalorum, Alanorum, Vnorum, Sueuorum illorumque ad Hispanias accessum et incolatum et principatum succincte perstringam ${ }^{64}$.

Se trata, pues, de una suerte de laus Hispaniae típica de la tradición literaria de origen peninsular, y que retrotrae sus orígenes al menos a época tardorrepublicana y altoimperial ${ }^{65}$. Las laudes Hispaniae fueron sublimadas en la Antigüedad tardía por Justino y, sobre todo, Isidoro, cuyas palabras tuvieron eco a lo largo de la tradición historiográfica medieval hispana. Sánchez de Arévalo también fue sensible a esta costumbre, pero la tamizó con una visión totalmente humanista en sintonía con los usos historiográficos italianos. En todo caso, la Compendiosa adquiere su forma final bajo la influencia de la Historia de rebus Hispanie y la Anacephaleosis. La primera parte sigue el esquema de la primera parte de la obra de Jiménez de Rada (y los capítulos 1 a 7 de la Anacephaleosis que, dicho sea de paso, también beben de Jiménez de Rada). La segunda parte coincide, a grandes rasgos, con todo el libro primero de la Anacephaleosis desde el capítulo 8 al 44, y con los libros 2 y 3 de la Historia de rebus Hispanie. En este punto conviene hacer un apunte que no deja de ser interesante y sobre lo que se insistirá un poco más adelante: la obra de Jiménez de Rada es también la fuente principal de Alfonso de Cartagena ${ }^{66}$.

${ }^{64}$ Trad.: En la primera, por supuesto, trataré de la salubridad del aire hispánico y de la fertilidad de su tierra, su fecundidad y riqueza de oro y plata y del resto de metales y minerales, también de la religión, lealtad, amabilidad, humanidad y diligencia de su pueblo; a continuación intercalaré brevemente los demás elogios y singularidades de los hombres y campo de Hispania y, por otro lado, la ubicación de las Hispanias, tanto su descripción con respecto a los demás territorios del orbe como la antigüedad de sus regiones; a continuación, los principados hispánicos y la erección de los reinos, pero también su división y cuándo, cómo y desde quiénes comenzaron, $\mathrm{y}$, finalmente, en qué reino acaso resida el título de Hispania; por otro lado, en esa parte hablaré sucintamente sobre la entrada a las Hispanias de griegos, fenicios y romanos y, a continuación, del inicio y origen del gobierno de godos, ostrogodos, vándalos, alanos, hunos, suevos, y sus llegadas, afincamientos y gobierno en las Hispanias.

${ }^{65}$ Una recopilación de laudes Hispaniae en latín desde la Antigüedad hasta el Renacimiento se puede encontrar en Antonio Alvar Ezquerra, «Spain», en Europatria, ed. de Francisco Oliveira, Coímbra, Universidade de Coímbra, 2013, pp, 433-480.

${ }^{66}$ Cfr. Y. Espinosa Fernández, La Anacephaleosis..., ed. cit., pp. 69-71. 
De Atanarico a Wamba, es decir, del capítulo 8 al 38 de la Anacephaleosis, Cartagena sigue casi al pie de la letra a Rada. Por otro lado, el texto de Rada coincide a su vez con la Historia Gothorum de Isidoro; según los estudios de Fernández Valverde ${ }^{67}$, la obra de este se encuentra incluida entera y al pie de la letra en la de aquel.

A partir del capítulo 39, en que se narra la vida de Wamba, la Anacephaleosis se desmarca de la Historia de rebus Hispanie y selecciona de manera más atenta los datos proporcionados por sus fuentes. Esto se debe, siguiendo el análisis de Espinosa Fernández ${ }^{68}$, a que «en general, a partir del momento en que la fuente es abundante, Cartagena omite con intención clara toda mención a la España musulmana y toda narración de hechos bélicos. En este sentido, Cartagena únicamente pretende hacer un catálogo de las hazañas, de las hazañas que a él le interesan desde el punto de vista del interés de su obra, y para ello no duda en omitir todo aquello que, aunque interesante y a veces incluso fundamental, pueda oscurecerle el fin que se ha marcado». Sánchez de Arévalo, por su parte, no duda en mantener el colorido de la narración histórica, y vuelve a incluir numerosos episodios de Jiménez de Rada, así como de Lucas de Tuy (cuyo Chronicon mundi cita en repetidas ocasiones para completar noticias de Rada o de Cartagena) o Diego Rodríguez de Almela. Quizás estas circunstancias sirven como explicaciones adicionales de por qué Arévalo silencia a Cartagena pero no duda en mencionar a Jiménez de Rada.

Más adelante, se puede observar con claridad meridiana la dependencia formal de Sánchez de Arévalo con la tradición que le precede. La tercera parte de la Compendiosa historia Hispanica comienza con el reinado de Pelayo, división lógica desde el punto de vista de la historiografía hispana, pues viene marcado por el final de la Hispania visigoda, la invasión musulmana y la creación de los reinos peninsulares modernos. El libro 2 de la Anacephaleosis comienza en este mismo punto, así como el libro 4 de la Historia de rebus Hispanie. La fórmula de mezclar materiales de ambas obras en la Compendiosa seguirá plenamente vigente hasta el final de esta parte, que termina con el reinado de Fernando III. A lo largo de ella, la presencia de Lucas de Tuy también es recurrente y explícita, así como la de Diego Rodríguez de Almela (modelo ocultado, como el de Cartagena, por ser contemporáneo suyo). Siempre en el prólogo a la Compendiosa, la dependencia al Tudense aparece mencionada expresamente por Arévalo (Comp. prol., 98-104):

${ }^{67}$ Juan Fernández Valverde, Roderici Ximenii de Rada. Historia de rebus Hispanie sive Historia Gothica, Turnhout, Brepols, 1987, pp. xxx-XxxI; Juan Fernández Valverde, Rodrigo Jiménez de Rada. Historia de los hechos de España, Madrid, Alianza Editorial, 1989, p. 34.

${ }^{68}$ J. Fernández Valverde, Rodrigo..., ed. cit., pp. 114-115. 
In tertia tandem parte sequentium regum omnium Hispanie successiones et succedendi ordinem; successus denique et clariora eorum gesta a reparatione Hispanie, inchoando uidelicet post infelicem cladem usque ad Fernandum III predictum, qui a Pelagio ipso primo post dictam cladem regnante XXXV rex fuit summatim repetam, nonnullaque addam a predictis scriptoribus intacta ${ }^{69}$.

Los «escritores ya mencionados» a los que se refiere son Lucas de Tuy y Jiménez de Rada. El fin de la tercera parte de la Compendiosa está condicionado por el propio fin de la Historia de rebus Hispanie. La cuarta parte sigue en deuda con la Anacephaleosis, pero es evidente que se sirve de otras fuentes, debido a que aquella es demasiado escueta en su narración y a que, con toda probabilidad, Arévalo tiene a disposición otras fuentes que, por desgracia, no he sido capaz de encontrar. Es el caso, por ejemplo, de las referencias explícitas a Ptolomeo de Luca (Comp. 4, 14, 51-53), o una velada a unos Annalia Anglorum (Comp. 4, 22, 76-77).

La otra gran deuda formal que tiene Arévalo con Alfonso de Cartagena es la articulación de la información en torno a cada rey o, si se prefiere, a la organización interna de los capítulos. La Anacephaleosis, desde que empieza a relatar la genealogía de los reyes hispanos en el capítulo vIII, presenta siempre la información de la manera siguiente ${ }^{70}$ :

- Identificación del monarca: nombre, lugar en la ordenación genealógica, parentesco.

- Cronología: se cita el año de comienzo del reinado y los años que dura el reinado. Cartagena ofrece hasta cuatro cronologías diferentes a lo largo de la obra (anno Domini, regni Hispaniae, a reparatione regni, ab ultima unione).

- Hechos señalados sucedidos durante su reinado, narrados de forma sumaria. Por regla general, se trata de referencias bélicas.

- Información acerca de la vida privada del monarca: matrimonios, hijos, concubinas.

- Muerte del rey y, en ocasiones, lugar de enterramiento.

${ }^{69}$ Trad.: Por fin, en la tercera parte retomaré de manera sumaria las sucesiones y orden de sucesión de todos los siguientes reyes de Hispania; a continuación, los sucesos y sus gestas más luminosas desde el restablecimiento de Hispania, a saber, empezando desde la desdichada derrota hasta el Fernando III ya mencionado, quien fue el trigésimo quinto rey desde Pelayo, el primero tras dicha derrota, y añadiré algunas cosas que no han sido tratadas por los escritores ya mencionados.

${ }^{70}$ Sigo la descripción de Y. Espinosa Fernández, La Anacephaleosis..., ed. cit., pp. 52-53. 
- Depingitur: se trata de una representación escrita del rey en relación a cómo se desarrolló su reinado, que tiene por finalidad que el lector se forme una imagen visual del monarca. Se le atribuyen un tipo de ropaje, una actitud, etc. Pueden describirse también en esta imagen coetáneos importantes del rey.

- Concurrencias: se ofrecen hasta cuatro gobiernos paralelos para cada rey, a saber, reinados de papas (in sede apostolica), emperadores del imperio romano (in solio imperii Romani), reyes francos y obispos de Burgos (in sede Burgensi).

Rodrigo Sánchez de Arévalo ofrece en la Compendiosa historia Hispanica una organización parecida, que no idéntica, influida sin duda por la Anacephaleosis. En cambio, no se presenta la información de manera tan monótona y lineal, sino que queda un margen algo mayor para la narración histórica y para la libertad compositiva. En términos generales, los datos que aparecen son los siguientes:

- Identificación del monarca: nombre, lugar en la ordenación genealógica, parentesco.

- Cronología: se cita el año de comienzo del reinado, así como los años que dura el reinado. La referencia temporal viene dada bajo la fórmula anno Domini; se trata por tanto de una referencia temporal internacional (en otras palabras, no se sigue la aera hispanica o cronología hispánica). Desde Pelayo, se incluye también al principio de cada reinado el número de peldaños que distancian a cada monarca de la invasión de los musulmanes (post cladem Hispanie) y de Atanarico, considerado el primer rey godo (post Atanaricum, primum regem Gothorum).

- Hechos señalados sucedidos durante su reinado, que pueden ser presentados antes o después de la vida privada del monarca (matrimonios, hijos y concubinas). Incluso puede mencionarse la muerte del rey antes de empezar a narrar su reinado propiamente dicho.

- Muerte del rey y, a veces, el lugar.

- Concurrencias. En este caso, Arévalo solo menciona a los papas y a los emperadores romanos que gobiernan en época de cada rey.

Hasta el final de la tercera parte de la Compendiosa, la narración de la vida de cada rey ocupa grosso modo un capítulo cada una. Es decir, el modelo cronístico de Cartagena tiene valor pleno. Sin embargo, en la propia tercera parte y a lo largo de toda la cuarta parte de la Compendiosa, la narración 
historiográfica desborda con creces la forma de crónica que caracteriza a la Anacephaleosis (Sánchez de Arévalo se ve sin duda influido por la mayor extensión en el relato de Jiménez de Rada y de Lucas de Tuy) y los acontecimientos de la vida de cada rey abarcan varios capítulos. Incluso cuando esto sucede, se mantienen todos los elementos de información enumerados que acompañan la vida de cada uno de los monarcas. En la tercera parte, la vida de Fernando I ocupa dos capítulos (Comp. 3, 26 y 27) en lugar de uno, pues el XXviI está dedicado a relatar las gestas de Rodrigo Díaz de Vivar. A Alfonso VI le corresponden también dos capítulos (Comp. 3, 29 y 30), pues el segundo de ellos, como indica su título, no habla del rey Alfonso, sino (Comp. 3, 30, 1-7):

De Geloira et Vrraca, filiabus Alfonsi, et de prole earum, et quomodo Alfonsus, rex Aragonum, duxit uxorem Vrracam, et de eius impudicitia, et qualiter uterque coniunx propter irreuerentiam Ecclesie pessima morte obierunt, et quomodo Aragonenses quendam a se in regem electum regno priuarunt et Ramirum monachum in regem erexerunt ${ }^{71}$.

Sánchez de Arévalo dedica a Alfonso VIII tres capítulos (los adicionales hablan de la victoria de las Navas de Tolosa y del asedio del castillo de Zorita y de su muerte), y a Fernando III otros dos. En lo que respecta a la cuarta parte, Alfonso X ocupa cinco capítulos, Sancho IV y Fernando IV dos, Alfonso XI cuatro, etc. Es decir, la necesidad de abordar los diferentes hechos históricos acaecidos bajo cada rey con extensión y detalle acercan definitivamente a la Compendiosa al mundo humanístico, pues empieza a romperse el encorsetado género cronístico que es, con todo, el modelo formal de Sánchez de Arévalo.

Queda por puntualizar un aspecto en lo concerniente a la deuda formal de Arévalo con la crónica. Su modelo más cercano es la Anacephaleosis; esta obra, por el enorme prestigio de su autor, marca las líneas maestras de la redacción histórica a sus coetáneos, que la asumen ya de manera convencional; sin embargo, el hipotexto preferido es la Historia de rebus Hispanie y, en menor medida, el Chronicon mundi de Lucas de Tuy, a quien nombra como una de sus lecturas preferentes, según lo visto arriba. Tres son, pues, los ovillos principales de la cesta con la que Arévalo teje su historia. Ahora bien, la relación entre estas tres obras entre sí y con la tradición es también muy

${ }^{71}$ Trad.: De Elvira y Urraca, hijas de Alfonso, y de su prole, y cómo Alfonso, rey de Aragón, tomó por esposa a Urraca, y de su falta de pudor y de qué manera uno y otro cónyuge sucumbieron a una muerte patética debido a su falta de respeto para con la Iglesia, y cómo los aragoneses privaron del reino a uno que habían escogido ellos y pusieron como rey a Ramiro el Monje. 
cercana, como es de suponer. Si la obra histórica de Cartagena debe muchísimo a Jiménez de Rada (su modelo buscado), no es menos cierto que Rada bebe, a su vez, de Lucas de Tuy. Así, Fernández Valverde ${ }^{72}$ señala lo siguiente en su edición de la Historia de rebus Hispanie: «La columna vertebral de las fuentes de la crónica la constituyen tres autores: S. Isidoro y Jordanes, para los dos primeros libros, y el Tudense para los restantes $\rangle^{73}$. La deuda es tal que describe la presencia de Lucas de Tuy en la obra de Rada como «el telón de fondo en el que se van enmarcando las demás crónicas, la mayoría de ellas ya conocidas por él, pero que sin embargo Jiménez de Rada las vuelve a considerar y a tomar de ellas los datos o hechos desechados por aquél» ${ }^{74}$. En ese sentido, la metodología de trabajo de Sánchez de Arévalo con la Anacephaleosis es de un parecido sorprendente a la de Jiménez de Rada. En cuanto a Lucas de Tuy, su Chronicon mundi es heredero del modelo isidoriano, sobre todo en lo que concierne a la forma, pues la concepción genealógica sigue la norma establecida por Isidoro, de acuerdo con la cual el material histórico no se organiza por unidades temporales, sino por reinados ${ }^{75}$. La Compendiosa historia Hispanica es heredera, por lo tanto, de la tradición historiográfica hispana y, aunque sus modelos directos son Alfonso de Cartagena, Jiménez de Rada y, en menor medida, Lucas de Tuy, la elección del género historiográfico y la disposición de la información remontan, de manera consciente o inconsciente, hasta la Historia Gothorum de Isidoro de Sevilla ${ }^{76}$. Arévalo conocía la obra de estos autores (el número de citas y la extensión de las mismas no permiten pensar otra cosa), por lo que la forma que presenta la Compendiosa es la suma, en mayor o menor medida, de todas las influencias anteriores $^{77}$. Lo mismo sucede con el contenido: a veces no se puede saber

${ }^{72}$ J. Fernández Valverde, Roderidi..., ed. cit., XxIX.

${ }^{73}$ Respecto a la dependencia de Jiménez de Rada con Lucas de Tuy, parece oportuno señalar que tampoco aquel cita a este como fuente, de manera análoga a lo que ocurre con Arévalo y Cartagena.

${ }^{74}$ Ibídem, p. XXXIII.

${ }^{75}$ Enrique Jerez Cabrero, El Chronicon mundi de Lucas de Tuy (c. 1238): técnicas compositivas y motivaciones ideológicas, Madrid, Universidad Autónoma, 2006, Tesis Doctoral.

${ }^{76}$ Vincent Serverat, «Sobre algunas tríadas sociales en la Hispania medieval: de Isidoro de Castilla a Rodrigo Sánchez de Arévalo», en Revista de Literatura Medieval, 19 (2007), pp. 207-241, demostró cómo Sánchez de Arévalo se dejó influir por Isidoro de Sevilla en otras obras, pues aplicó teorías suyas (en el caso del estudio de Serverat, acerca de la división de los estamentos), aunque pasadas por el filtro del aristotelismo, en otras obras de su producción escrita, como el Speculum uite humane (1468).

${ }^{77}$ Un resumen sobre la tradición historiográfica hispana desde Isidoro de Sevilla hasta Sánchez de Arévalo se puede leer en Josué Villa Prieto, «La ideología goticista en los prehumanistas castellanos: Alonso de Cartagena y Rodrigo Sánchez de Arévalo. Sus consideraciones sobre la unidad hispanovisigoda y el reino astur-leonés», en Territorio, Sociedad y Poder, 5 (2010), pp. 125-145. Se mantienen tanto modelos formales (género cronísitico) como ideológicos (en especial, el goticismo de los monarcas castellanos). 
a qué historiador sigue, pues en todos ellos se narran, de forma general, las mismas cosas.

Al lado de estos modelos se dejan sentir otros modelos buscados que completan la idea de historia que Arévalo tiene en mente y que le proporcionan información sobre aspectos concretos de su narración. Es el caso de Vicente de Beauvais (1194-1264), Martín de Opava y, con toda certeza, Sicardo de Cremona (otro autor que no ha sido posible localizar). Así, el Speculum historiale de Vicente de Beauvais surte de material a Arévalo para narrar los orígenes de los pueblos vándalo y huno en la primera parte de la Compendiosa. El propio Speculum, el Chronicon pontificum et imperatorum de Martín de Opava y la Chronica uniuersalis de Sicardo proporcionan gran parte de los datos que Arévalo necesita para elaborar las concurrencias a cada rey hasta el final de la tercera parte, pues los tres vivieron en el siglo XIII, es decir, hasta época de Alfonso X en el mejor de los casos, cuya vida se narra ya, como ha quedado dicho, en la cuarta parte de la Compendiosa.

El último gran grupo de modelos buscados lo constituyen los autores antiguos cuyas obras complementan el uso omnipresente de Rada y Cartagena al elaborar la descripción geográfica y de las riquezas de Hispania. Resultan pertinentes en este punto las observaciones que hizo Tate ${ }^{78}$ respecto a la Compendiosa, pues denotan un cambio de modelo en Sánchez de Arévalo:

En la Historia Hispanica de Ruy Sánchez de Arévalo, publicada en Roma en 1470 , se da el primer paso hacia la fusión del tradicional elogio de España con los nuevos datos geográficos de los humanistas. En lugar del corto capítulo inicial del Anacephaleosis tenemos media docena dedicados a varios aspectos de la topografía y geografía histórica de la Península. En lugar del encomio de Isidoro o del lamento de Jiménez de Rada, él nos presenta el primer panorama detallado, forjado no solo de sus lecturas, sino también de observaciones personales del territorio [...]. Saca sus datos con preferencia de escritores que a él le parecen testigos oculares, como Mela, al cual añade Plinio, Solino y Estrabón. Estos datos sobre la antigua riqueza del país, los complementa con otros de la época contemporánea con el propósito de establecer una estrecha relación, según la vieja tesis aristotélica, entre el fondo físico del país y la disposición de los habitantes. Esta aportación suya, valiosísima en sí misma, apuntaba una crónica de España del mismo corte que las historias de Italia contemporáneas, pero a la moda española.

${ }^{78}$ Vid. Robert Brian Tate, «La geografía humanística y los historiadores del siglo XV», en Actas del cuarto congreso internacional de hispanistas, ed. de Eugenio de Bustos, Salamanca, Universidad de Salamanca, 1982, pp. 691-698. 
La presencia recurrente de Estrabón, en su traducción latina, como fuente de inspiración (e imitación) constituye un caso muy significativo de la permeabilidad de Arévalo al Humanismo que se está desarrollando en Italia, sin duda, la más potente y exitosa de las convenciones de su época ${ }^{79}$. Aparte de Isidoro, se puede constatar la presencia de otros autores como Justino, Jordanes, Pablo el Diácono (con la salvedad de que es ya plenamente medieval) $\mathrm{y}$, en menor medida, Pomponio Mela y Solino, quienes completan la nómina de geógrafos consultados ${ }^{80}$. Quizás, el cambio más importante en esta innovación historiográfica venga dado por un comentario del propio Arévalo, que pretende, siquiera de manera retórica, ofrecer como garantía de fiabilidad el empirismo de la observación personal (Comp. prol., 117-125):

Dabo ego enarrandis rebus testimonium uerissimum, ueluti qui partim corpus dedit historie, et Hispaniarum oras litoraque et angulos a mari usque ad mare seriose ac personaliter peragraui atque conspexi, nec dubito a quibusdam multa in rebus ipsis scripta fore que forte a tramite uere narrationis deuiasse audio, pro eo quia nihil oculata fide sed per audita a remotis narrata scriptitarunt. Tunc enim, ut putamus, res quelibet certissimo comprobatur testimonio cum eodem utitur relatore quo teste ${ }^{81}$.

Pero, ¿de qué serviría elegir un modelo sin voluntad ni de imitarlo, ni de evocarlo, ni de competir con él192 Una vez explicada la arquitectura de la Compendiosa historia Hispanica, se puede decir algo acerca de cómo

${ }^{79}$ Cfr. Guillermo Alvar Nuño, «Las fuentes geográficas en la Compendiosa historia Hispanica de Rodrigo Sánchez de Arévalo: el caso de Estrabón», en Philologia, Universitas, Vita. Trabajos en honor de Tomás González Rolán, ed. de José Miguel Baños Baños, M. ${ }^{\mathrm{a}}$ Felisa del Barrio Vega, M. ${ }^{\mathrm{a}}$ Teresa Callejas Berdonés y Antonio López Fonseca, Madrid, 2014, pp. 45-52.

${ }^{80}$ No se puede afirmar, aunque tampoco descartar, que Arévalo conociera al geógrafo Ptolomeo, ya sea por las traducciones latinas de la tradición greco-árabe, ya sea por la traducción de su Geographia por el humanista siciliano Giacomo da Scarperia en el siglo XV, cfr. Josué Villa Prieto, «El saber geográfico en una época de transición: la representación de Europa en los tratados españoles del cuatrocientos», Territorio, Sociedad y Poder, 7 (2012), pp. 191-220, p. 195. A pesar de que no he encontrado referencias directas, Arévalo lo menciona como fuente en Comp. 1, 5.

${ }^{81}$ Trad.: Daré yo testimonio muy veraz de los asuntos que se narren, como alguien que en parte ha puesto su cuerpo en esta historia, y ha recorrido y contemplado con seriedad y en persona las orillas y litorales de las Hispanias y sus rincones de uno a otro mar; y no dudo de que algunos escribieron mucho sobre estos mismos asuntos, que oigo quizás desviados del camino de una narración veraz por aquello de que no escribieron una y otra vez nada con testimonio ocular, sino de oídas con lo narrado por terceros. Entonces, lo cierto es que, como pensamos, cualquier cosa se comprueba con testimonio más preciso cuando lo emplea el mismo relator que ha sido testigo del mismo.

${ }^{82}$ Tomo esta pregunta de Antonio Alvar Ezquerra, «Tipología de los procedimientos intertextuales en la poesía latina antigua», en IX Congreso Español de Estudios Clásicos: Madrid, 27 al 30 de septiembre de 1995, Madrid, Sociedad Española de Estudios Clásicos, 1998, vol. 5, pp. 3-16, p. 15. 
Sánchez de Arévalo emplea el recurso de la intertextualidad ${ }^{83}$. Lo hace de dos maneras diferentes: La primera deriva de la influencia de los modelos formales de la Compendiosa, y consiste en las referencias intertextuales concretas bajo la forma de citas, plagios y alusiones (por usar la terminología de Genet$\mathrm{te}^{84}$ ) a la Anacephaleosis de Alfonso de Cartagena (el texto más próximo en el tiempo y el más empleado, si no de manera cualitativa, desde luego sí de manera cuantitativa), a la Historia de rebus Hispanie de Jiménez de Rada y al Chronicon mundi de Lucas de Tuy. Los pasajes en los que se evidencian de una forma u otra estas tres obras sirven, a lo largo de toda la Compendiosa, para hacer avanzar la narración. En lo que respecta a las concurrencias de papas y emperadores y al origen de los pueblos germanos, el relato se elabora siguiendo las referencias textuales a Martín de Opava, Vicente de Beauvais y a Sicardo; por último, la primera parte de la Compendiosa echa mano de los geógrafos griegos y romanos, así como de Jordanes, Isidoro y Pablo el Diácono. De modo que no se trata solo de autores en los que Arévalo se inspira, sino que el contenido de aquellas obras constituye la materia misma de su crónica.

La segunda manera de emplear las fuentes permite completar la narración escueta de los historiadores de los que es heredero con numerosos exempla. De este modo, la Compendiosa logra un colorido y una profundidad que van más allá de los logros de sus antecesores. La exuberancia en el manejo de fuentes tiene, pues, una finalidad moral transparente que Arévalo evidencia al principio mismo de su obra (Comp. inc., 7-12):

Pro ampliore historie ornatu, inter ipsa Hispanica gesta inseruntur breui priscorum Romanorum, Grecorum et aliorum exterorum antiquorum clarissima gesta, dicta et insignia documenta ad cuiusuis principantis, potentis seu nobilis ac priuati hominis instructionem ${ }^{85}$.

Así, en efecto, después de narrar cada hecho histórico, lo pone en paralelo con episodios similares bien de las Sagradas Escrituras, bien de los clásicos grecolatinos. Esta manera de proceder no se aleja mucho de lo que hizo para su propia obra Liber de officio et munere ducis, capitanei et castellani, en

${ }^{83}$ Para una relación exhaustiva de los autores que componen las citas intertextuales de la Compendiosa historia Hispanica, así como su distribución a lo largo de la obra, vid. G. Alvar Nuño, Estudio..., ed. cit., pp. 108-133.

${ }^{84}$ Vid. Gérard Genette, Palimpsestes. La littérature au second degré, París, ed. du Seuil, 1982, p. 8.

${ }^{85}$ Trad.: Para mayor ornato de esta historia, entre los propios sucesos hispánicos se insertan con brevedad los sucesos, dichos y enseñanzas reseñables más ilustres de los originarios romanos, griegos y otros antiguos pueblos extranjeros para instrucción de cualquier gobernante, hombre de poder o noble y también de cualquier persona particular. 
donde los exempla se presentan siempre en el siguiente orden: ejemplos bíblicos, hazañas de los clásicos (griegos y latinos), gestas de reyes y nobles hispánicos ${ }^{86}$. En el caso de la Compendiosa, puesto que se cuenta siempre primero el hecho acaecido a los personajes hispanos, que para eso es una Historia Hispanica, los exempla bíblicos y clásicos aparecen por norma general después del hecho que comentan. Esta utilización de las fuentes goza de otra virtud no menos importante: la comparación continua de los personajes hispánicos con personajes clásicos facilitaba la comprensión de la narración por parte de los intelectuales de todo el continente europeo ${ }^{87}$.

\section{Conclusiones}

A lo largo de estas páginas, se ha intentado poner en relación la figura de Alfonso de Cartagena con la de su discípulo Rodrigo Sánchez de Arévalo, haciendo hincapié en tres aspectos: la filiación intelectual de este respecto a su maestro y valedor Alfonso de Cartagena, el contacto continuo con los humanistas italianos y, por último, la importancia y calidad de la actividad diplomática de ambos. Estos tres aspectos son claves que permiten una compresión profunda de las razones que llevaron al maestro y al alumno a la escritura de sendas obras históricas, la Anacephaleosis y la Compendiosa historia Hispanica.

En ese sentido, ambas obras intentan situarse en un contexto internacional -de ahí la elección del latín como lengua de escritura- en el que Castilla empieza a desarrollar un discurso histórico propio enfrentado al que estaban proponiendo los humanistas italianos del Cuatrocientos. Si bien es cierto que la Anacephaleosis tuvo poco alcance fuera de las fronteras peninsulares, influyó decisivamente en la concepción y estructura de la Compendiosa historia Hispanica, que fue bien conocida en ese momento. Esto último queda bien demostrado al confrontar el texto de la Compendiosa con el texto de la Anacephaleosis, lo que permite encuadrarla dentro de una tradición historiográfica que tiene como inspiración principal la obra de Alfonso de Cartagena, pero que remonta sus fuentes y finalidad hasta Isidoro de Sevilla. Además, el

${ }^{86}$ Cfr. Antonio López Fonseca y José Manuel Ruiz Vila, Rodrigo Sánchez de Arévalo. Deberes y funciones de generales, capitanes y gobernadores, Madrid, Escolar y Mayo, 2011, p. 35. En realidad, Arévalo se inspiraba en el Valerio de las historias escolásticas de España de Rodríguez de Almela, pues en él se presentan los ejemplos morales que se quieren ilustrar dando preferencia siempre al episodio bíblico, después al anecdotario clásico, y por último a los ejemplos hispanos.

${ }^{87}$ Cfr. Josué Villa Prieto, «Europa y los humanistas peninsulares del siglo XV», en ¿Europa?, ed. de Ana Isabel González González y Patricia Herrero de la Escosura, Oviedo, Universidad de Oviedo, 2011, pp. $87-98$, p. 95 
empleo de citas de textos clásicos como argumentos de autoridad aproxima la Compendiosa a los usos del humanismo italiano, y, si se suma el amplio número de citas de autores medievales, la obra adquiere una dimensión claramente internacional.

Recibido: $15 / 05 / 2018$

Aceptado: 19/07/2018 
$\cos$

\section{La influencia de Alfonso de Cartagena \\ en la Compendiosa historia Hispanica de Rodrigo Sánchez de Arévalo}

Resumen: Este artículo se propone estudiar el lugar que ocupa la Compendiosa historia Hispanica de Rodrigo Sánchez de Arévalo (1470) en el contexto de su época, con especial atención a la influencia que ejerció su maestro Alfonso de Cartagena en él. Para ello, se analiza la relación entre ellos; a continuación, la influencia de la retórica clásica en la labor historiográfica de ambos autores, la relación de la Compendiosa frente al humanismo italiano y, por último, su relación con la tradición historiográfica hispana, en especial con la Anacephaleosis de Alfonso de Cartagena.

Palabras Clave: Rodrigo Sánchez de Arévalo. Alfonso de Cartagena. Historiografía latina del siglo Xv. Fuentes. Humanismo. Retórica clásica.

\section{Alfonso de Cartagena's influence on Rodrigo SÁncheZ de ARÉvalo's Compendiosa HISTORIa HisPaNiCA}

ABSTRACT: The objective of this article is to study what place Rodrigo Sánchez de Arévalo's Compendiosa historia Hispanica (1470) occupies in its age context, and to stress the influence that his master Alfonso de Cartagena exerted on him. To do this, it will be first described the relationship that linked them; then, the influence that Classical rhetoric had on their historiographical endeavour and what was the intellectual positioning the Compendiosa took with regard to Italian humanism and, finally, its links to Hispanic historiographical tradition, granted that its most important source was Alfonso de Cartagena's Anacephaleosis.

KeYwords: Rodrigo Sánchez de Arévalo. Alfonso de Cartagena, $\mathrm{Xv}^{\text {th }}$ Century Latin Historiography. Sources. Humanism. Classical Rhetoric. 